УДК 81 '37

DOI 10.23951/1609-624X-2020-2-68-75

\title{
БИБЛЕЙСКАЯ СИМВОЛИКА КАМНЯ В РУССКОЙ ФРАЗЕОЛОГИИ
}

\author{
Н. С. Гнездилова
}

Национальный исследовательский Томский государственный университет, Томск Томский государственный педагогический университет, Томск

Введение. Представлены результаты исследования реализации библейской символики камня в значениях образных фразеологизмов русского языка и текстах, актуализирующих их семантику. Актуальность работы обусловлена научным интересом к изучению функционирования образной символики камня в языковых единицах библейского происхождения.

Целью работы является описание особенностей символизации камня в библейских текстах, а также анализ образных фразеологизмов, транслирующих эту символику.

Материал и методы. Исследование выполнено в рамках когнитивного и лингвокультурологического подходов к изучению образных средств языка, которые метафорически, символически, аллегорически выражают представления о различных явлениях действительности. Используются методы структурно-семантического, концептуального и контекстного анализа, представленные в работах по когнитивной теории метафоры (Дж. Лакофф, М. Джонсон, А. Н. Баранов, Ю. Н. Караулов, А. П. Чудинов, и др.), лексической и фразеологической образности (Н. Ф. Алефиренко, О. И. Блинова, Н. А. Илюхина, Г. Н. Скляревская, Е. А. Юрина и др.), лингвокультурологии (М. Л. Ковшова, В. В. Красных, В. Н. Телия и др.).

Результаты и обсуждение. В рамках данного исследования проведен анализ символического отображения камня в библейских текстах, описана семантика иносказательного характера, актуализированная в современных художественных и публицистических текстах, а также семантика и текстовое функционирование фразеологизмов, транслирующих символику камня. Первоначальным источником описываемых устойчивых образных выражений послужила книга Священного Писания Ветхого и Нового Завета - Библия.

Заключение. Полученные результаты анализа демонстрируют аксиологически значимый фрагмент русской языковой картины мира. Данные корпусного исследования свидетельствуют об активном функционировании библейской символики камня в современном русском языке. Библейская символика камня в русской фразеологии актуализирует значения: суть, самая важная часть чего-либо; затруднение, проблема, с которыми кто-либо сталкивается при занятии каким-нибудь делом; осуждение кого-либо, высказывание кому-либо неодобрения; разрушение до основания чего-либо, а также некоторые другие.

Ключевые слова: библейская символика, символ, камень, образные средства, русский язык, лингвокультурология.

\section{Введение}

Библейская символика, представленная в образных средствах русского языка, плодотворно исследуется в рамках лингвокультурологического, психолингвистического, дискурсивно-прагматического подходов современной лингвистики [1-11]. Актуальность исследования библейской символики камня обусловлена научным интересом к изучению символического функционирования образа камня и его образной языковой репрезентации.

Объектом анализа в данной статье являются библейские по происхождению фразеологизмы, функционирующие в современном русском художественном и публицистическом типах дискурса. Цель работы - охарактеризовать образные фразеологизмы русского языка, которые включают в свою структуру наименования с семантикой 'камень' и восходят к текстам христианского Священного Писания, выявить качества и свойства камня, послужившие основанием символизации и метафориза- ции, исследовать функционирование образных средств, транслирующих библейскую символику камня в современных дискурсивных практиках.

\section{Материал и методы}

В данной статье анализируются устойчивые образные выражения современного русского языка библейского происхождения, в которых актуализирована символика камня. Источником языкового материала послужила текстовая база Национального корпуса русского языка [12].

В фокусе исследовательского внимания находятся аспекты символического функционирования в художественном и публицистическом дискурсе образа камня, зафиксированного в библейских по происхождению фразеологизмах, направления символического переосмысления данного образа в современной русской лингвокультуре. Под библеизмами понимаются слова или выражения афористического или фразеологического характера, во- 
шедшие в употребление из библейских текстов [13, c. 86].

Символ невозможно создать искусственно или изобрести, за ним можно только наблюдать как за средством общения, с помощью которого мы получаем какую-либо информацию. Символ служит средством сообщения информации о действительности, которые при другом способе общения или оказались бы затемнены из-за недостаточности нашего языка, или слишком сложны для адекватного выражения. Таким образом, символ не может сводиться, как, например, знак, к чистой форме, и его невозможно понять вне религиозного, культурного или метафизического контекста [13, с. 6].

Приступая к изучению библейской символики, необходимо сказать, что Библия является не только сакральным текстом христиан, но и литературным памятником, источником различных мифологических сюжетов, в котором отражаются реалии, культура, система ценностей и общественно-политический уклад прошлого. По словам В. А. Мендельсон, процессу фразеологизации библейских цитат «способствовали содержательное богатство соответствующих текстовых фрагментов, их высокие эстетические достоинства», а мощный семиотический потенциал библейских образов, экспрессивность и лаконичность афористических выражений «обеспечивают возможность их переосмысления и дальнейшего содержательного обогащения» $[14$, с. 3$]$.

\section{Результаты исследования}

Корпусное исследование показало, что в современных публицистических и художественных текстах активно функционируют 5 библейских фразеологизмов, включающих лексему камень. Это такие фразеологизмы, как:

1. Краеугольный камень 'суть, самая важная часть чего-либо' - Я полагаю в Сионе камень краеугольный, избранный, драгоценный; и верующий в Него не постылдтся. Итак Он для вас, верующих, драгоченность, а для неверующих камень, который отвергли строители, но который сделался главою угла, камень претыкания и камень соблаз$\underline{\mathrm{Ha}}$ о который они претыкаются, не покоряясь слову, на что они и оставлены; восходит к Новому Завету, 1-е послание Петра (гл. 2, ст. 6-8).

2. Камень преткновения 'затруднение, проблема, с которыми кто-либо сталкивается при занятии каким-нибудь делом' - И будет Он освящением и камнем преткновения, и скалою соблазна для обоих домов Израиля, петлею и сетью для жителей Иерусалима; восходит к Ветхому Завету, Книга пророка Исайи (гл. 8, ст. 14), также встречается в Новом Завете (Евангелие от Луки).

3. Не оставить камня на камне 'разрушить до основания что-либо' - И выйдя, Иисус шел от хра- ма; и приступили ученики Его, чтобы показать Ему здания храма. Иисус же сказал им: видите ли все это? Истинно говорю вам: не останется здесь камня на камне, все будет разрушено; восходит к Евангелию от Марка (гл. 13, ст. 2) и Евангелию от Матфея (гл. 24, ст. 1-2).

4. Камни возопиют 'о негативных событиях, ситуациях, которые вызывают возмущение, негодование' - Когда Иисус приблизился к спуску с горы Елеонской, все множество учеников начало в радости велегласно славить Бога за все чудеса, какие видели они, говоря: благословен Царь, грядущзий во имя Господне! мир на небесах и слава в вышних! И некоторые фарисеи из среды народа сказали Ему: Учитель! запрети ученикам Твоим. Но Он сказал им в ответ: сказываю вам, что если они умолкнут, то камни возопиют. И когда приблизился к городу, то, смотря на него, заплакал о нем и сказал: о, если бы и ты хотя в сей твой день узнал, что служст к миру твоему!; Евангелие от Луки (гл. 19, ст. 39-40).

5. Бросить камень в кого-либо 'осудить коголибо, высказать кому-либо неодобрение' - $A$ когда на следующее утро Он вновь пришел в храм, около Него собралось множество людей, и Он стал проповедовать им. Тут книжники и фарисеи привели женщину, уличенную в прелюбодеянии, и, поставив ее перед Ним, говорят Ему: Учитель! Эту женщину застали во время прелюбодеяния, а согласно закону, данному нам Моисею, таковых надо побивать камнями. Что Ты на это скажешь? Говорили же они это, испытывая Его, чтобы иметь обвинение против Него. А Иисус, наклонись, писал чтото пальщем на земле. Но поскольку они продолжали неотступно спрашивать Его, Он поднял голову и сказал им: кто из вас безгрешен, тот пусть первым и бросит в нее камень. А Сам, наклонясь, вновь стал писать на земле; восходит к Евангелию от Иоанна (гл. 8, ст. 7).

Помимо вышеназванных пяти фразеологизмов достаточно активно функционирует один прецедентный текст (6) Кто из вас без греха, первый брось в нее камень, восходящий к Новому Завету, Евангелие от Иоанна (гл. 8, ст. 7).

Рассматривая библейскую символику камня, следует отметить, что, по данным интернет-ресурса «Библия онлайн» [15], лексема камень встречается в Библии 95 раз, что свидетельствует о значимости этого концепта в передаче религиозных смыслов. Образ камня символически связывается с фигурой Иисуса Христа, который в Послании Петра называется «камнем живым», драгоценным камнем: «Отложив всякую злобу и всякое коварство, $u$ лицемерие, и зависть, и всякое злословие, как новорожденные младенщы, возлюбите чистое словесное молоко, дабы от него возрасти вам во спасе- 
ние; ибо вы вкусили, что благ Господь. Приступая к Нему, камню живому, человеками отверженному, но Богом избранному, драгоценному, и сами, как жсивые камни, устрояйте из себя дом духовный, священство святое, чтобы приносить духовныле жертвы, благоприятные Богу Иисусом Христом». Петр призывает людей отринуть пороки, посредством слов приблизиться к Иисусу (камню живому). Далее в этом же библейском тексте разворачивается «строительная» метафора камня, символизирующая возведение духовного храма, начало которому положено Иисусом: «Я полагаю в Сионе камень краеугольный, избранный, драгоценный; $u$ веруюший в Него не постьлдтся. Итак Он для вас, веруюших, драгоценность, а для неверуюших камень, который отверали строители, но который сделался главою угла, камень претыкания $и$ камень соблазна, о который они претыкаются, не покоряясь слову, на что они и оставленьл».

«Строительная» метафора камня подводит нас к символическому осмыслению фразеологизма камень преткновения, демонстрируя природу его происхождения со значением 'затруднение, проблема, с которыми кто-либо сталкивается при занятии каким-нибудь делом'. Эта символика реализуется в первых трех фразеологизмах из приведенного ранее списка: краеугольный камень, камень преткновения и не оставить камня на камне. Рассмотрим актуальную семантику данных идиом, представленную в современном публицистическом и художественном типах дискурса.

Фразеологизм краеугольный камень употребляется для описания и характеристики следующих явлений и процессов:

1. Политической жизни: политических процессов, внешнеполитических отношений между государствами на международной арене, внутренней политики государства - Краеугольный камень стратегии ЕС в отночении восточных стран все хотят быть членами Евросоюза («Эксперт», 2004); Смеем утверждать: перекройка карть России, укрупнение регионов - краеугольный камень в провозглашенной три года назад путинской вертикали власти (Б. Березовский, М. Коданев. «Независимая газета», 2003); Вопрос о власти сегодня краеугольный камень любых рассуждений о реформах в российском обществе (В. Шурыгин. «Завтра», 2003).

2. Основных научных теорий, которые составляют основу научной парадигмы, $-B$ настоящее время этот язык - под названием «реляционная модель данныху - составляет краеугольный камень быстро развивающейся и актуальной области - построения баз данных (В. А. Успенский, 2002); О сущчествовании долгоживущих возбужденных молекул знали гораздо раньше, чем смо- гли понять их природу. Только в 1943 г. академику А. Н. Теренину удалось блестяще разгадать загадку этих молекул: причина их долгожительства триплетное состояние. Этим был заложен краеугольный камень в здание современной фотохимии (В. Кронгауз, 1968); Л. С. Выготский формулирует закон о превращении интерпсихического в интрапсихическое - «краеугольный камень марксистской психологии». Отсюда понимание обучения как взаимодействия ребенка и взрослого, положение об опережающей роли обучения, понятие зонь ближайшего развития (П. А. Мясоед. Теории в «Вопросы психологии», 2004).

3. Экономической жизни: с помощью фразеологизма краеугольный камень описывается специфика экономики сельскохозяйственного сектора, а также особенности внешнеэкономических взаимоотношений разных стран - Это планирование «от земли», от «рабочих мест», это «краеугольный камень» всей сельской экономики, и это планирование вытянет за собой обновленное социальноэкономическое планирование сельских территорий и создаст условия работы и жизни на земле, которые сегодня ограничены недостаточными для сельской территории, а потому «ущзербными», градостроительными схемами территориального планирования (Гуськов А. Е. Вступление России в ВТО, 2012); Недаром ряд аналитиков уже провел своеобразную параллель между этим экономическим пространством и Европейским объединением угля и стали, с которого в 50-е годы началось франко-германское сближение, заложившее краеугольный камень нынешнего Европейского Союза (А. Колычев. Москва станет ближе к евро, 2001).

4. Медицинской науки: способы иммунотерапии при аллергии, основные элементы какой-либо научной теории - Краеугольный камень лечения всех видов аллергий - антигистаминные лекарства («Встреча», 2003); Знаешь, эдипизм, конечно, краеугольный камень классического психоанализа (Д. Симонова. Сорванная слива, 2002).

5. Военной сферы, развития военно-политических отношений между двумя странами - Таким образом, каждой стороне пока удается гнуть свою линию: американиьы убеждают Москву в том, что «краеугольный камень» за 30 лет своего существвования сильно пообтерся и нужды в нем, равно как и в вытекаюших из Договора по ПРО соглашениях, сегодня нет (В. Волков. «Известия», 2001).

6. Религиозно-духовной жизни, важнейших элементов религиозно-духовной жизни, религиозного знания - Антитеза Бог - Сатана - Краеугольный камень средневекового мировоззрения - предполагала присутствие в обществе слуг дьявола, отвергавиих нормы христианской нравственности 
(С. А. Еремеева. Лекции по истории искусства, 1999); Безусловное признание исхождения Святого Духа от Сына (filioque), непорочного зачатия, первенства и непогрешимости римского папь составляет краеугольный камень их вероучения (Е. Цимбаева. «Русский католицизм» как общественно-философское течение XIX века, 1996).

7. Идеологии, идеологических взглядов и ценностей - Безусловный приоритет общечеловеческих иенностей, бескорыстное служение прекрасному - вот краеугольный камень для писателей, поддерживающих перестройку (В. Война. Трибуна «Апреля», 1989); Вот краеугольный камень этой проблемы: УБИВАТЬ, ЧТОБЫ НЕ БЫТЬЬ УБИТЫМ (В. Доценко. Тридцатого уничтожить!, 2000).

По данным Национального корпуса русского языка (НКРЯ), идиома камень преткновения используется по отношению к характеристике следующего ряда феноменов общественной жизни:

1. Непреодолимых препятствий, возникающих в общении, мышлении, деятельности: процессов экономики внутри предприятия, межличностного взаимодействия, экономического планирования Размер предельно допустимого оборота малого предприятия - камень преткновения в дискуссии («Известия», 2002); И тут был камень преткновения в наших отношениях все последние семь лет, а заочно началось раньше (А. Найман. Славный конец бесславных поколений, 1994); Бесспорно, главный камень преткновения сегодня - вопросы финансирования («Строительство», 2003).

2. Неотъемлемой и существенной части какихлибо социальных феноменов: специфичности школьного образования, основы прекращения локальных конфликтов - В рамках мировой войны выделяют Отечественную, и она наше все. Мировая - камень преткновения для школьников. Средний ответ: началась то ли в 39-м, то ли в 40-м (дату капитуляичи Японии не знаем, о действиях в Африке, Греции, о Сопротивлении, об участии Индии, о судьбе Италии информированность близка к нулю) (В. Иванницкий. «Знание - сила», 2005); Что касается третьего пункта, то Масхадов был категорически не согласен. Требовал: вначале вы выведите войска, а потом мы, мол, сами организуем сдачу оружия... Так и не смогли мы тогда обойти этот камень преткновения. Через несколько дней вновь встретились. Теперь, кроме Масхадова, присутствовали Ширвани Басаев (брат Шамиля) и Мовлади Удугов. Мы друг друга проинформировали об обмене убитыми и ранеными (Г. Трошев. Моя война, 2000-2001).

3. Важных элементов экономических процессов - Еще один камень преткновения - железнодорожные тарифы. С учетом транспортной составляющей отпускная иена кузбасского угля, до- ставленного в Центральную Россию, увеличивается вдвое (И. Сербина. «Известия», 2002).

4. Неотъемлемой части какой-либо научной теории - Вот этой разниць в содержании легких и тяжелых изотопов (она называется «изотопнылм фракиионированием») ученые до сих пор найти не могли, и она составляла камень преткновения всех теорий (М. Вартбург. «Знание - сила», 2013); И здесь, на мой взгляд, главный камень преткновения - это теоретическая нерешенность вопроса о соотношении понятий психики и деятельнос-

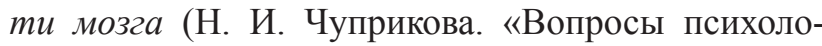
гии», 2004).

Контекстный анализ показал, что можно выделить ряд актуальных для дискурсивного употребления фразеологических значений этих образных выражений. Идиомы краеугольный камень и камень преткновения метафорически обозначают основополагающую идею какой-либо концепции (в науке), самый важный и значимый элемент общественной структуры (в политике, экономике), важный компонент какой-либо деятельности, методики, а также - начало, отправную точку, импульс для развития и становления чего-либо (при характеристике социальной деятельности). Кроме того, фразеологизм камень преткновения также выражает в контекстах следующие актуальные значения: спорный момент в дискуссии, неразрешимое противоречие в отношениях, препятствие, мешающее осуществить задуманное.

По результатам поиска в Национальном корпусе русского языка и анализу контекстов с фразеологическим выражением не оставить камня на камне видно, что оно используется для метафорического обозначения ряда исторических, социальных и психологических явлений и ситуаций:

1. Спортивной жизни, победы одной спортивной команды в матче с другой - Самарский клуб камня на камне не оставил от «Анжи» («Известия», 2002).

2. Уничтожение чего-либо до основания в результате военного конфликта - Денэг не дал, чтоб мой дом оставыл. Его взорвал. Он не дал денег генералам, чтобы его дом не бомбили, и от его дома камня на камне не оставили. Он стал перечислять, что только-только завез в дом новую мебель, новые окна поставил, привез из-за границь новые машины (К. Сурикова. Чеченец, 2003).

3. Моды на определенные элементы внешнего вида/гардероба: смена модных тенденций - Ho эпоха Людовика XIV камня на камне не оставила от естественности. Отныне женскую фигуру венчало сложное сооружение - так называемьй «фонтанж»: сочетание высокой прически и жесткого чепиа с бесчисленными рядами рюшей $и$ оборок. Кожу скрывал слой белил, дополненный 
мушками. В общуем, в правление «короля-солнцее» настоящее солниее как бы и отменили («Семейный доктор», 2002).

4. Военной сферы, процессов, происходящих в оборонной отрасли страны, - Встревоженныц таким положением дел Главком Сухопутных войск Владимир Семенов летом 1995 года был вынужден почти силком затащзить министра оборонь на военный совет СВ и там камня на камне не оставил от скороспельх и вредных прожектов министерских горе-реформаторов (В. Баранец. Генштаб без тайн. Книга 1, 1999).

5. Медицины - B 1985 году появилась книга «Кровопролитие в медицине. Личное свидетельство». А в 1989-м - другая книга «Медичинская мафия в государстве коррупчииџ. Автором обеих книг, которые камня на камне не оставили от израильского здравоохранения, был Юлий Нудельман. Он приехал в Израиль из Москвь в 1971 году. Работал хирургом в больнице «Рамбам», заведовал хирургическим отделением в больнице «Барзилай» в Аикелоне. Участвовал в войнах Судного дня и «Мир Галилее», оперировал на поле боя (А. Бовин. Пять лет среди евреев и мидовцев, или Израиль из окна российского посольства, 1999).

6. Культурной жизни, специфичности театральных постановок - Народнылй артист Республики подобрался к Гоголю, чтобы камня на камне не оставить на гоголевском творении; он поступил с особой злобой, точно он с Гоголем сводил счеть;; не просто сломал пьесу Гоголя, а около полутора года ломал: со смыслом! Гоголь смеялся здоровым смехом: Мейерхольд убил здоровый смех; театр Гоголя столетия несли «на традициях» изить театров; Мейерхольд разбил щуиты, Гоголь свалился и раскололся на тысячу кусков, где восстановить Гоголя? По-моему, перечитать Гоголя, пока гоголевский текст не изорван Мейерхольдом. Вместо этого в первых рецензиях о постановке набат: безобразие! (Ю. Елагин. Темный гений, 1998).

7. Социально-исторических процессов преобразования общества - Он же весь город разнесет! И очень просто. Девятидюймовки, что вы думаете! Камня на камне не оставит. «Он» был, конечно, мятежный броненосец «Потемкин», ставший на Одесском рейде. Из-за чего произошел тот мятеж, все говорили по-разному. Но известно было, что матросы перебили офицеров, выкинули красный флаг и чего-то требуют от города (И. Ратушинская. Одесситы, 1998); Впрочем, Стольпин, конечно, меньше всего думал о благополучии крестьян: после того как в пятом году мужики камня на камне не оставили от его саратовского имения - не просто простить, а сохранить после этого теплое, доброе чувство в душе к этим мужикам может только... ну, святой человек (С. Бабаян. Ротмистр Неженцев, 1995-1996).

8. Туристической сферы, проблемы загрязнения экологии в туристических районах - Не заботься мы о природе, от нее ничего бы не осталось, как на Лазурном берегу. Хотя, по правде сказать, там туристов гораздо больше и оберегать природу от них сложнее. Говорят иногда: "И слава Богу, что в Бретани такой климат, а то туристы бы от нее камня на камне не оставили». Понятно, почему даже в Бретани отночение к туристам не всегда восторженное. Некоторых они начинают раздражать (А. Муразова. Земля людей. Потомки короля Градлона, 1997).

9. Архитектурно-строительной сферы, стилей и направлений - Ярмак ярко показал на расширенном совещзании, что Гольдман рабски подбирает крохи со стола западной архитектурной мысли. А молчун Гольдман с презрительной своей ульббочкой неожиданно прошепелявил и прокартавил длинную речь, где камня на камне не оставил от самой идеи русофильства в строительстве (С. Юрский. Чернов, 1972-1978).

10. Профессиональной свободы - Но я здесь свободный человек, и пока мою эту свободу не тронули, я тоже никого не трону. А вот если тут которые найдутся, чтобы наше нынешнее положение фермерское переменить, то тут я вам в точности обешаюю: мы от вашего города камня на камне не оставим. Мы вам, мать вашу так, не павианыл. Мы вам, мать вашу так, ошейники себе на горло положить не дадим! (А. Стругацкий, Б. Стругацкий. Град обреченный, 1972).

11. Характера человека, отношений между людьми - И ждал с минуты на минуту Мещерякова, будто бы уже видел его перед собою и ему говорил эти же слова, его направлял на истинный путь. Ждал Брусенкова, чтобы камня на камне не оставить от тяжелого брусенковского упрямства. Ему казалось - он ждет еще и ещуе каких-то людей, чтобы в ту же минуту они поверили. Поверили бы всему, чему должен и обязан верить нынче человек (С. Залыгин. Соленая Падь, 1967).

Библейская символика метафорического выражения бросить камень в кого-л. связана с образом камня как символом орудия кары, наказания, который ассоциативно связан с древнейшим способом казни преступников - забрасыванием камнями. В контекстах представляет следующие актуальные значения:

1. Социальные отношения, отношения между человеком и государством, социальные задачи государства - Но кто посмеет бросить камень в многодетную мать за стремление, как ей казалось, протянуть руку и воспользоваться всеми благами громадного наследства (А. Г. Колмогоров. Мне до- 
ставшееся: Семейные хроники Надежды Лухмановой, 2012); Кто, кроме маргинальных эмансипе, станет возражать, чтобы число браков в 2, 3 (а не в 1, 3 раза, как сегодня) переросло число разводов?! Точно так же никто не посмеет бросить камень в такие иелевые задачи, как снижение травматизма, доступность качественной медицинской помощи для любого горожанина, а также обеспечение всех желаюших трудиться на «хорошо оплачиваемой работе, соответствующей потребностям» (К. Черемных, Н. Львова. Однако, 2009).

2. Характеристика профессиональной деятельности, этические нормы профессионала - Может, дело было не совсем так. Вишневский терпеть не мог Петровского. Потом узнавал у других, но завеса секретности была плотная, правды не узнать. Комментарий: я столько оперировал, столько раз ошибался, что не могу бросить камень в хирурга. Однако после Брянска, где не было страховки опытных коллег и приходилось всех оперировать, чтобы как-то спасти, никогда не брался за «чужие» операции, когда можно было передать более опытному специалисту. За время конгресса много виделся с Аркашей. Они переехали на другую квартиру, соединились с семьей Татьяны, сестры Аннь (Н. Амосов. Голоса времен, 1999); Конечно, чью бы сторону ни принял немец, он все равно оказался бы в сложном положении. И в данной ситуации Ральфу правильнее было промолчать. Но гонщик Williams не смог преодолеть искушения бросить камень в огород соседа, с которым ведет упорную борьбу за статус первого номера команды. "Я не пай-мальчик и тоже атакую, когда это необходимо. Но глупо рисковать аварией в борьбе за лидерство, если можно получить гарантированные шесть очков за второе место», - такова философия гонок по Ральфу Шумахеру! Впрочем, чтобы понять эту философию до конца, слова «когда это необходимо», видимо, следует переводить как: «если передо мной идет не Михаэль» (В. Маккавеев. «Формула», 2002).

3. Психологическая характеристика образа жизни человека - Шла к интеллигентам, а попала $к$ незатейливым людям, пусть и с высшим образованием. Мы славно поработали и славно отдохнем! И книжки читаем, вон, целльй икаф... Музычку, что ли, поставить? Но кто посмеет бросить камень в трудящегося скопидома? Он никому ничего не задолжал. Он работает, а потом честно пьет пиво и слушает музыку, которая ему по вкусу. И сервизы покупает тоже по собственному вкусу (Д. Драгунский. Смоляное чучелко, 2011).

Результаты поиска в Национальном корпусе русского языка и анализ контекстов с фразеологизмом-библеизмом камни возопиют, который восходит к Евангелию от Луки (синодальный перевод
1816-1862) показали, что данный фразеологизм используется для образного обозначения социальных и психологических явлений и ситуаций:

1. Обозначения человеческих страстей: $-B c e$, что есть у меня, все, что, может быть, есть - все швыряю сегодня на бельий алтарь Афродить!! Так думал я. А она - смеялась. А она - подошла к столу и выпила залпом ещуе сто пятьдесят, ибо она была совершенна, а совершенству нет предела... Железнодорожная - Черное выпила - и сбросила с себя что-то лишнее. «Если она сбросит, - подумал я, если она, следом за этим лишним, сбросит и исподнее - содрогнется земля и камни возопиют». А она сказала: «Ну, как, Веничка, хорошо у меня?» (В. Ерофеев. Москва - Петушки, 1970).

2. Характеристики условий жизни людей Спешно отремонтировать нужники, бараки, места личной гигиены еtс. так, чтобы они не носили на себе следы судорожно наведенного марафета, тоже невозможно. Если это особлаг по своему режиму, то там безмолвные камни возопиют - что бы ни говорили тюремщчики и запуганные заключенные. Комиссии СПЧ достаточно было выслушать показания камней. После чего составить объективный доклад, основанный на тех источниках, которые по своей природе не могут врать (М. Соколов. Известия, 2013).

\section{Заключение}

Полученные результаты исследования показывают лингвокультурологически значимый фрагмент русской языковой картины мира. Данные корпусного исследования демонстрируют активное метафорическое функционирование фразеологизмов-библеизмов с символикой камня в современном художественном и публицистическом дискурсах.

Можно сделать вывод о том, библейская символика камня в русской фразеологии актуализирована следующими значениями: суть, самая важная часть чего-либо; затруднение, проблема, с которыми кто-либо сталкивается при занятии каким-нибудь делом; осуждение кого-либо, высказывание кому-либо неодобрения; разрушение до основания чего-либо; негативные события, ситуации, которые вызывают возмущение, негодование.

Библеизмы с символикой камня в русской фразеологии употребляются для описания и характеристики следующих явлений и процессов: политической жизни; элементов научной теории; экономической жизни; медицинской науки; военной сферы; религиозно-духовной жизни; фундаментальной науки; идеологии; непреодолимых препятствий, возникающих в общении, мышлении, деятельности; неотъемлемой и существенной части каких-либо социальных феноменов; важных элементов экономических процессов; неотъемлемая 
часть какой-либо научной теории; спортивной жизни; разрушение/уничтожение чего-л. до основания в результате военного конфликта; моды на определенные элементы внешнего вида/гардероба; военной сферы; медицины; культурной жизни (театральной сферы); социально-исторических процессов преобразования общества; туристической сферы и экологии; архитектурно-строительной сферы; профессиональной свободы; характера человека и др.
Библейская символика камня связана с его лингвокультурной семантикой, что наиболее ярко демонстрируют фразеологизмы библейского происхождения.

Исследование выполнено в рамках реализащии гранта Российского научного фонда № 18-1800184 «Образная система русского языка в полидискурсивном пространстве современных коммуникаций».

\section{Список литературы}

1. Алефиренко Н. Ф. Фразеологическая репрезентация христианского мировосприятия (на материале восточнославянских языков) // Мир православия: сб. науч. ст. Волгоград, 1998. Вып. 2. С. 126-131.

2. Алексеев А. А. Текстология славянской Библии / РАН: Институт русской литературы (Пушкинский Дом). СПб.: Изд-во РАН, 1999. 254 с.

3. Верещагин Е. М. Библейская стихия русского языка // Русская речь. 1993. № 1. С. 78-96.

4. Мокиенко В. М. Фразеологические библеизмы в современном тексте // Библия и возрождение духовной культуры русского и других славянских народов. К 80-летию Русской Северо-Западной Библейской Комиссии (1915-1995). СПб.: ТОО ТК «Петрополис», 1995. C. $143-159$.

5. Гак В. Г. Особенности библейских фразеологизмов в русском языке в сопоставлении с французскими библеизмами // Вопросы языкознания. 1997. № 5. С. 55-65.

6. Гвоздарев Ю. А. Библеизмы в русской фразеологии (к истории освоения) // Эволюция лексико-фразеологического и грамматического строя русского языка: межвуз. сб. науч. работ / под ред. С. Г. Шулежковой. Магнитогорск, 1994. С. $26-34$.

7. Оноприенко С. Библеизмы современного русского языка: дис. канд. филол. наук. Воронеж, 1997. 189 с.

8. Дубровина К. Н. Энциклопедический словарь библейских фразеологизмов. М.: Флинта: Наука, 2010. С. 4-6.

9. Бурканова О. П. Фигуры противоположности в богослужебном тексте (на материале немецкого языка) // Научный вестник Воронежского гос. арх.-строит. ун-та. Современные лингвистические и методико-дидактические исследования. 2010. Вып. 1 (13). С. 40-47.

10. Семенова В. И. Фразеологические единицы русского языка, восходящие к Библии // Вопросы истории русского языка. Тула: Изд-во Тульского гос. пед. ин-та, 1968. С. 44-50.

11. Стариченок В. Д. Большой лингвистический словарь. Ростов н/Д: Феникс, 2008. 811 с.

12. Национальный корпус русского языка. URL: http://www.ruscorpora.ru (дата обращения: 21.01.2020).

13. Купер Дж. Энциклопедия символов. М.: Золотой Век, 1996. 401 с.

14. Мендельсон В. А. Фразеологизмы библейского происхождения в английском и русском языках. Казань: Новое знание, 2009. 155 с.

15. Библия онлайн. URL: https://bible.by/symphony/word/10/173/ (дата обращения: 21.01.2020).

Гнездилова Наталия Сергеевна - аспирант, младший научный сотрудник, Национальный исследовательский Томский государственный университет (пр. Ленина, 36, Томск, Россия, 634050); старший преподаватель, Томский государственный педагогический университет (ул. Киевская, 60, Томск, Россия, 634061).

E-mail: natal-gnezdilova@yandex.ru

Материал поступил в редакциию 17.01.2020.

\section{DOI 10.23951/1609-624X-2020-2-68-75}

\section{BIBLICAL SYMBOLISM OF STONE IN FIGURATIVE MEANS OF RUSSIAN LANGUAGE}

\section{N. S. Gnezdilova}

National Research Tomsk State University, Tomsk, Russian Federation

Tomsk State Pedagogical University, Tomsk, Russian Federation

Introduction. This article presents the results of a study on the functioning of the biblical symbolism of a stone in Russian linguistic culture expressed through figurative means of the Russian language. The relevance of the work is due to scientific interest in the study of the functioning of the figurative symbolism of a stone in biblical texts.

The purpose of this work is to describe the specifics of the symbolization of the image of a stone in biblical texts expressed in the semantics of language units and figures of speech; to consider various aspects of the metaphorical interpretation of the image of a stone, based on the symbolism of the spiritual and religious traditions of the Christian culture. 
Material and methods. The research is carried out within the framework of cognitive and linguistic cultural approaches to the study of figurative means of language that metaphorically, symbolically, and allegorically express various phenomena of reality. The methods used are structural-semantic, conceptual and contextual analysis presented in the works on the cognitive theory of metaphor by G. Lakoff, M. Johnson, A. Baranov, Y. Karaulov, A. Chudinov, etc.), lexical and phraseological imagery (N. Alefirenko, N. Ilyukhina, G. Sklyarevskaya, E. Yurina, etc.), linguoculturology (M. Kovshova, V. Krasnykh, V. Telia, etc.). The source of the linguistic material is the text base of the National corpus of the Russian language.

Results and discussion. This study analyzes the symbolic representation of a stone in biblical texts; describes the semantics of the allegorical character relevant in modern fiction and non-fiction, as well as the semantics and textual functioning of phraseological units that translate the symbolism of a stone. The original source of the described stable figurative expressions was the book of Holy Scripture of the old and New Testaments - the Bible.

Conclusion. The results obtained demonstrate a cognitively and axiologically significant fragment of the Russian linguistic picture of the world. The data of the corpus research indicate the active functioning of the biblical symbolism of a stone in the modern Russian language.

Keywords: biblical symbolism, symbol, stone, figurative means, Russian language, cultural linguistics

\section{References}

1. Alefirenko N. F. Frazeologicheskaya reprezentatsiya khristianskogo mirovospriyatiya (na materiale vostochnoslavyanskikh yazykov) [Phraseological representation of the Christian worldview (based on the material of the Eastern Slavic languages)]. Mir pravoslaviya: sb. nauchnykh statey [The world of Orthodoxy: a collection of scientific articles]. Volgograd, 1998. Pp. 126-131 (in Russian).

2. Alekseyev A. A. Tekstologiya slavyanskoy Biblii [Textology of the Slavic Bible]. RAN: Institut russkoy literatury (Pushkinskiy Dom) [RAS: Institute of Russian Literature (Pushkin House)]. Saint Petersburg, RAS Publ., 1999. 254 p. (in Russian).

3. Vereshchagin E. M. Bibleyskaya stikhiya russkogo yazyka [The biblical element of the Russian language]. Russkaya rech, 1993, no. 1, 78-96 p. (in Russian).

4. Mokiyenko V. M. Frazeologicheskiye bibleizmy v sovremennom tekste [Phraseological biblisms in a modern text]. Bibliya i vozrozhdeniye dukhovnoy kul'tury russkogo i drugikh slavyanskikh narodov. K 80-letiyu Russkoy Severo-Zapadnoy Bibleyskoy Komissii (1915-1995) [The Bible and the revival of the spiritual culture of the Russian and other Slavic peoples. On the occasion of the 80th anniversary of the Russian Northwest Bible Commission (1915-1995)]. Saint Petersburg, Petropolis Publ., 1995, pp. 143-159 (in Russian).

5. Gak V. G. Osobennosti bibleyskikh frazeologizmov v russkom yazyke v sopostavlenii s frantsuzskimi bibleizmami [Features of biblical phraseological units in Russian in comparison with French biblical units]. Voprosy yazykoznaniya - Voprosy Jazykoznanija (Topics in the study of language), 1997, no. 5, pp. 55-65 (in Russian).

6. Gvozdarev Yu. A. Bibleizmy v russkoy frazeologii ( $\mathrm{k}$ istorii osvoyeniya) [Bibleisms in Russian phraseology (on the history of development)]. In: Evolyutsiya leksiko-frazeologicheskogo i grammaticheskogo stroya russkogo yazyka: Mezhvuz. sb. nauch. rabot [Evolution of the lexicophraseological and grammatical structure of the Russian language: Interuniversity collection of scientific works]. Ed. S. G. Shulezhkova. Magnitogorsk, 1994, pp. $26-34$ (in Russian).

7. Onopriyenko S. Bibleizmy sovremennogo russkogo yazyka. Dis. kand. filol. nauk [Biblical phraseological of the modern Russian language]. Voronezh, 1997. 189 p. (in Russian).

8. Dubrovina K. N. Entsiklopedicheskiy slovar' bibleyskikh frazeologizmov [Encyclopedic dictionary of biblical phraseological units]. Moscow, Flinta: Nauka Publ., 2010, pp. 4-6 (in Russian).

9. Burkanova O. P. Figury protivopolozhnosti v bogosluzhebnom tekste (na materiale nemetskogo yazyka) [Figures of the opposite in the liturgical text (based on the material of the German language)]. Nauchnyy vestnik Voronezhskogo gos. arkh.-stroit. un-ta. Sovremennye lingvisticheskiye i metodiko-didakticheskiye issledovaniya, 2010, no. 1 (13), pp. 40-47 (in Russian).

10. Semenova V. I. Frazeologicheskiye edinitsy russkogo yazyka, voskhodyashchiye k Biblii [Phraseological units of the Russian language that go back to the Bible]. Voprosy istorii russkogo yazyka [Issues of the history of the Russian language]. Tula, Tula State Pedagogical University Publ., 1968, pp. 44-50 (in Russian).

11. Starichenok V. D. Bol'shoy lingvisticheskiy slovar' [Large linguistic dictionary]. Rostov on Don, Feniks Publ., 2008. 811 p. (in Russian).

12. Natsional'nyy korpus russkogo yazyka [National Corps of the Russian Language] (in Russian). URL: http://www.ruscorpora.ru (accessed 21 January 2020).

13. Kuper Dz. Entsiklopediya simvolov [Encyclopedia of symbols]. Moscow, Zolotoy Vek, 1996. 401 p. (in Russian).

14. Mendel'son V. A. Frazeologizmy bibleyskogo proiskhozhdeniya $v$ angliyskom i russkom yazykah [Phraseological units of biblical origin in English and Russian]. Kazan, Novoye znaniye Publ., 2009. 155 p. (in Russian).

15. Bibliya onlayn [Bible online]. URL: https://bible.by/symphony/word/10/173/ (accessed 21 January 2020] (in Russian).

Gnezdilova N. S., National Research Tomsk State University (pr. Lenina, 36, Tomsk, Russian Federation, 634050); Tomsk State Pedagogical University (ul. Kiyevskaya, 60, Tomsk, Russian Federation, 634061). E-mail: natal-gnezdilova@yandex.ru 